\title{
O DESENVOLVIMENTO RELIGIOSO: UMA HIPÓTESE PSICOLÓGICA
}

\author{
RELIGIOUS DEVELOPMENT: \\ A PSYCHOLOGICAL HYPOTHESIS
}

Mauro Martins AMATUZZI ${ }^{1}$

\begin{abstract}
RESUMO
Esta pesquisa, num primeiro momento, constrói um modelo psicológico de desenvolvimento religioso, descrevendo 9 etapas ao longo da vida. Isso é feito a partir de outras pesquisas sobre o desenvolvimento humano, mas também a partir da experiência do autor trabalhando com grupos populares onde se refletia sobre o crescimento pessoal. As experiências básicas que caracteri-zam as etapas do desenvolvimento pessoal foram definidas como sendo: confiança, construção simbólica do mundo (pela linguagem), coragem e iniciativa, escolha pessoal, intimidade, gerare cuidar, liberdade, simplesmen-te viver, e entregar-se. A partir daí as etapas do desenvolvimento religioso descreveram essas experiências em seu aspecto de contato com o objeto religioso. -Em um próximo artigo serão apresentados, e analisados à luz dessa teoria geral, depoimentos de história religiosa pessoal.
\end{abstract}

Palavras-chaves: desenvolvimento psicológico, religiosidade, religião, desenvolvimento religioso.

\begin{abstract}
This research, in a first moment, constructs a psychological model for religious development describing nine developmental stages along the life span. This construction is based on other researches about personal development, and also on the author experience reflecting with common people groups about personal development. Each stage is defined following some central basic experiences: truth, symbolic construction of the world (language), courage and enterprise, personal choice, intimacy, generating and nursing, freedom, just living, and surrender. The religious development stages, then, describe these experiences at the view point of the relationship with the religious object. - This article will be

Endereço para correspondência: Rua Marechal Deodoro, 1099 - Campinas-SP CEP 13030-310 - Telefone 289-2635
\end{abstract}

(1) Prof. Dr. PUC-Campinas.

E-mail: amatuzm2@cosmo.com.br 
continued in another one, when sone personal repports of the religious history are presented and analysed according to the lights of this model.

Key words: psychological development, religion, religiousness, religious development

\section{INTRODUÇÃO}

A necessidade de aprofundar o tema do desenvolvimento religioso surgiu de uma pesquisa anterior sobre a fenomenologia da experiência religiosa (Amatuzzi, 1998a, 1998b). Os depoimentos colhidos faziam pensar em níveis diferentes de maturidade religiosa, relacionados com a maturidade humana geral. A descrição da experiência religiosa precisava, então, ser completada por uma descrição dos possíveis caminhos do crescimento ou transformação religiosa. Com isso entramos em nosso tema atual.

Tendo por base os depoimentos já colhidos, a experiência do autor em trabalhos psicológicos junto a indivíduos e grupos (Amatuzzi e col., 1996), e consultada a literatura referente ao desenvolvimento, a idéia era montar uma teoria, uma hipótese geral, sobre esses possíveis caminhos do desenvolvimento religioso. É importante esclarecer desde já, no entanto, que essa hipótese, muito embora pudesse se apresentar sob a forma de etapas ou fases seqüenciais mais ou menos definidas, não teria intenção de se tomar uma escala para uso avaliativo. A intenção permaneceu sendo a de descrever para compreender, muito mais no sentido de preparar o agente de escuta ampliando seus horizontes face as diversas possibilidades, do que lhe fornecendo um instrumento de classificação.

A partir dessa teoria ou hipótese geral, uma vez formulada, retomaríamos aos depoimentos, não tanto para, confirmá-la ou não (num modelo metodológico de simples verificação), mas sim, principalmente, para que sua utilidade compreensiva ficasse ilustrada e aperfeiçoada (num modelo metodológico de construção e aperfeiçoamento de teoria). A finalidade continua sendo, pois, a de aprofundar a compreensão da natureza do fenômeno religioso, a partir de uma leitura acurada da experiência das pessoas.

Apresentaremos aqui o caminho que nos conduziu até à hipótese geral, a leitura de alguns depoimentos ilustrativos, e finalmente uma discussão da própria hipótese à luz dos depoimentos e de outros estudos. Antes de tudo, porém, será preciso definirmos alguns conceitos que foram básicos para esse estudo.

\section{CONCEITOS BÁSICOS}

No ponto de partida está a idéia de senso religioso. Refere-se essa expressão àquilo que em nós, seres humanos, está na base das questões de sentido, enquanto questões potencialmente radicalizáveis. Deixando-nos conduzir pela indagação do sentido (que sentido tem tal coisa? Por que aconteceu assim?), acabaremos formulando a pergunta pelo sentido último, mais radical (qual o sentido deste mundo? que sentido tem minha vida? que sentido mais profundo se esconde em tal acontecimento?). O que está por trás de tal processo é o senso religioso. Embora o termo "religioso" possa incluir uma referência ao sagrado, enquanto algo particular, o que é mais básico nessa conceituação aqui, é a referência a um último, o que, ao contrário de particular, é abrangente, envolvente e, afinal, transcendente (isto é, transporta-nos para uma outra ordem de consideração).

As indagações do senso religioso acabam desembocando em tomadas de posição no que diz respeito ao significado último das coisas. Levam, portanto, a uma forma religiosa pessoal. Esta forma pode variar bastante, indo desde o assumir de uma religião já sistematizada externamente, até formas diversas de espiri- 
tualidade ou de vivências filosóficas, explícitas ou implícitas. O que há de comum entre posições tão diferentes é sempre a referência a um último. Religião está sendo entendida, portanto, no sentido geral de re-ligação (com esse último), capaz de situar a pessoa no todo, e orientar sua vida. Algo como a estrutura de orientação e devoção, de que fala Erick Fromm (1974/1944), que é alguma coisa da qual todos sentimos a necessidade, embora nem sempre lidemos com essa necessidade da mesma forma.

Uma terceira idéia central se baseia no fato de que a mesma forma religiosa, externamente ou objetivamente considerada, pode estar nas pessoas de modos diferentes no que diz respeito ao seu grau de centralidade psicológi-ca. Quer dizer, o valor estruturante da forma religiosa para com a vida psíquica, pode variar bastante. Ou ainda, em outras palavras, a reli-gião pode estar mais ou menos enraizada na pessoa, tendo uma influência maior ou menor em sua visão de mundo e em sua vida concreta. Referimo-nos a isso c omo o grau de enraizamento da religião ou da forma religiosa.

Vivência religiosa vem a ser a experiência da pessoa no campo religioso, ou seja, no campo das indagações pelo último. Cada um pode ter uma história a contar quanto a isso; seja um ateu, um budista, ou um evangélico. No entanto para alguns, nessa história ocorreram experiências religiosas num sentido mais específico. Trata-se de acontecimentos marcantes para a tomada de posição em relação a um sentido último, e que foram assumidos com esse significado. Uma experiência como essa pode se dar a propósito de acontecimentos ordinários mas vistos sob nova luz, ou de acontecimentos extraordinários que são vividos como símbolos.

O termo fé relaciona-se com a firmeza das posições da pessoa diante da vida, firmeza essa que faz supor uma relação básica de confiança pela qual vivemos. A fé se torna religiosa quando explicita uma referência a uma realidade última.

O desenvolvimento religioso pode ser entendido como o desenvolvimento pessoal no campo das indagações por um sentido último (campo religioso). Para descrevermos esse desenvolvimento em suas possibilidades é necessário articular 3 dimensões: o desenvolvimento psicológico, a ocorrência de experiências marcantes para a própria definição de um sentido último de vida, e o encontro com alguma tradição religiosa viva. O desenvolvimento psicológico nos dá as possibilidades dentro das quais podemos conceber as coisas nesse campo do sentido. As experiências marcantes de vida determinam também o que concebemos e a forma como vivemos. $\mathrm{E}$, finalmente, a tradição religiosa corresponde a tudo aquilo que recebemos em nossa cultura como forma de pensamento e experiência acumulada da humanidade no que diz respeito às questões de um significado último.

\section{COMO FOI SE FORMANDO A HIPÓTESE}

O percurso, na verdade, foi bastante longo. Ele começou com uma primeira visão geral do desenvolvimento pessoal, baseada em Piaget, em seu Seis Estudos de Psicologia (Piaget, 1967). Ali descrevíamos o desenvolvimento em termos de uma progressiva construção de um conceito de eu, inicialmente bastante egocêntrico. Ele vai se tornando mais realista na medida em que a pessoa vivencia as oposições eu-mundo (no primeiro ano de vida), eu-outros (antes da adolescência) e eu-verdade (na adolescência). Acrescentamos, porém, a consideração do que poderia estar se passando na vida adulta, inspirando- nos em autores que se voltavam também para essa fase de vida, Jung com a metanóia no meio da vida, por exemplo, e Maslow com sua hierarquia de necessidades humanas (ver, por exemplo,Jung, 1979/1934, e Maslow, s/d).Com isso acrescentamos uma outra oposição na constituição do eu, e que denominamos eu-vida. Através dessa oposição a pessoa já se abre, mais explicitamente, para as questões de um significado último (pois se vê face a uma vida queé maiorque sua própria individualidade). 
Fi-camos então com os seguintes momentos marcantes no percurso do desenvolvimento: a descoberta do mundo, coincidindo com a primeira constituição de um eu; a descoberta do outro enquanto afetivamente independente; a descoberta de uma verdade mais profunda do que aquela recebida dos pais; e, por fim, a descoberta da vida enquanto não se limitando à minha individualidade. Isso teve uma primeira expressão em um livro de divulgação, intitulado Crescimento e Ajuda (que teve uma $2^{\mathrm{a}}$ edição com o título Retratos da Vida) (Amatuzzi, 1980 e 1988).

Alguns anos mais tarde, trabalhando com grupos populares no sentido de refletir sua própria experiência devida (Amatuzzi, 1996), fomos levados a descrever duas outras etapas. Uma, entre os 7 anos e o começo da adolescência, quando o menino ou a menina se confrontavam com o desafio de superar certas limitações no que diz respeito a habilidades ou competências, e com isso ganhar a auto-estima de alguém capaz. E outra já na idade madura, mas antes da abertura para a transcendência da vida. Uma espécie de segunda adolescência. Nesta época muitas pessoas falavam de um questionamento de seus papéis anteriores e suas rotinas adquiridas. Ocorriam reviravoltas devida, muitas vezes sentidas como libertadoras. Surgia uma nova experiência de liberdade, um reencontro consigo próprio para além das obrigações ou deveres, e provavelmente uma vida mais saudável, ou, ao menos, o desejo disso. Mas também muitas pessoas simplesmente continuavam a "carregar o fardo da existência" com abnegação, com uma insatisfação mais ou menos calada, sem se colocar a possibilidade de mudanças. Parecia uma fase de vida que continha seus desafios próprios, e que, como as outras, podia ser mais ou menos bem vivida ou aproveitada em termos de crescimento pessoal. Passamos a descrever, então, as etapas de vida a partir de seus desafios próprios em termos de desenvolvimento, e, conseqüentemente,descrever as possibilidades de não enfrentamento desses desafios, e seus efeitos sobre a vida da pessoa. Estávamos descrevendo seis fases de vida (não tanto mo mentos de descoberta), marcadas por desafios próprios: o bebê no primeiro ano, a criança pequena até 6 anos, o menino ou menina, a adolescência até a vida adulta, a segunda adolescência na idade adulta mais avançada, e, finalmente, a maturidade até a velhice.

Paralelamente a isso, mas também motivados pelo trabalho com grupos populares, interessamo-nos pela experiência religiosa, pois parecia estar muito presente como fator determinante, ou mesmo motivador, do envolvimento das pessoas nesses grupos de reflexão, ou simplesmente em suas formas de vida. No trabalho, nas leituras e reflexões, foi ficando logo claro que essa experiência tinha uma relação estreita como desenvolvimento, seja no sentido de facilitá- lo, seja no de obstruí-lo. Indiferente não era, a não ser quando a vivência religiosa era por demais superficial (sem enraizamento). Procuramos compreender como poderia estar se apresentando a experiência religiosa em cada uma daquelas 6 etapas até agora descritas.

Por essa época entramos em contato com a pesquisa de Fowler (1992/1981) sobre os Estágios da Fé, e através dela pudemos reencontrar seus inspiradores, dentre os quais Erickson e Kohlberg. O conceito de fé, para Fowler, não deixa de ser, ao menos aparentemente, portador de uma certa ambigüidade. Por um lado ele diz que "a fé é um aspecto genérico da luta humana para achar e manter sentido, e que ela pode ou não exprimir-se pela religião" (p.83). Todo mundo pode ter uma fé, e isso não tem relação necessária com religião. Mas, por outro lado, ele também fala que a fé se relaciona com o "mistério que nos envolve" (p.39), com as "condições últimas da existência" (p.84), com uma "realidade transcendente" (p.168), e, em sua forma mais desenvolvida, inclui uma "intencionalidade divina"(p.169). Ao menos implicitamente a fé seria, portanto, religiosa, enquanto promotora de uma re-ligação com o último.

Talvez pudéssemos entender Fowler se disséssemos que ela é o que dá sentido à vida e 
aquieta a pessoa; é a ligação com um sentido último; trata-se de um "repousar o coração", e alinhar a vida. Supõe, portanto, uma "inquietação do coração". Mas quando ocorre esse repousar, é porque algo se mostra ou se constitui como firme, o que justifica dizer que a fé vem a ser uma confiança. Na medida em que isso vai se explicitando em todas as suas dimensões, esse pólo de firmeza se mostra como último, como transcendente. Na verdade podemos colocar a fé em algo que não o mereça, mas em seu dinamis-mo ela procura sempre esse algo totalmente firme, absoluto. Por isso está implícito em qual-quer fé um pólo absoluto, um centro transcen-dente de valor e poder. A fé é realmente essa firmeza e determinação pela qual vivemos, mas ela se torna explicitamente religiosa quando pode falar de seu pólo absoluto e transcendente. Talvez devêssemos dizer, então,que, enquanto movimento humano interior que fundamenta o viver, é só implicitamente que ela contém a referência a algo absolutamente firme (não mais do que como uma direção pressentida, formulada a posteriori). Será a experiência religiosa, enquanto experiência da manifestação desse algo, que explicitará a fé como religiosa. Isso se aproxima do que diz Fowler no fim de seu livro, onde ele lança a hipótese de que, com a conversão, ocorre uma re-significação da fé.

É interessante recordarmos aqui os estágios do desenvolvimento moral de Kohlberg, e os do desenvolvimento psicossocial de Erikson, pois eles ajudam a entender os estágios da fé, de Fowler.

Kohlberg ver,por exemplo, Camino,1998, p.113) descreve 3 níveis de julgamento moral, cada um deles com 2 estágios, aqui exemplificados através de frases típicas (e com as idades aproximadas estimadas por Fowler).

Nível pré-convencional:

1- "não faço isso para não ser punido": moralidade heterônoma (até 6 anos);

2 -"não faço isso porque desejo a recompensa": moralidade de troca instrumental (depois dos 7 anos, até 12).
Nível convencional:

3 -"não faço isso porque não é esperado que eu faça": moralidade das expectativas interpessoais (adolescência e juventude);

4 -"não faço isso porque quebraria uma lei": moralidade de sistema social e consciência (jovem adulto, acima dos 21 anos).

Nível pós-convencional:

5 -"não faço isso porque tenho a obrigação de não fazer": moralidade dos direitos individuais (adulto em torno dos 35 em diante);

6 -"não faço isso porque não é certo, não importa o que digam": princípios éticos universais (em torno dos 60 em diante).

O grau mais elevado de julgamento moral é, pois, aquele que se baseia em princípios universais.

Erikson (1998) expressa seus estágios psicossociais em termos de conflitos centrais e de qualidades psicológicas que aí emergem. Ele fala de 8 conflitos, que poderiam ser mais ou menos associados a idades (Erickson,1998, p. 52). Comentaremos cada um deles com frases de Joan Erikson, num capítulo da mesma obra.

\section{Confiança básica vs. Desconfiança bási- ca (ESPERANÇA) (0-2 anos).}

Nós precisamos reconhecer o fato de que sem uma confiança básica o bebê não pode sobreviver. Disso decorre que todas as pessoas vivas têm uma confiança básica e com ela, até certo ponto, a força da esperança. (...) Embora a sobrevivência seja difícil sem um mínimo de desconfiança para nos proteger, a desconfiança pode contaminar todos os aspectos das nossas vidas e nos privar de amore companheirismo com os seres humanos (p.90).

2. Autonomia vs. Vergonha, Dúvida (VONTADE) (2-3 ANOS).

Certamente todos os pais lembram como (...) os filhos (...) se tornaram surpreendentemente determinados, agarrando colheres e brinquedos, prontos a serem independentes. (...) 
Quanto mais forte a vontade, mais eles realizam. (...) Mas existem limites; quando eles são rompidos e as coisas ficam fora do controle, pode haver uma reversão para a insegurança e uma falta de autoconfiança que termina em vergonha e dúvida quanto às suas capacidades (p.91).

\section{Iniciativa vs. Culpa (PROPÓSITO) (3-6 anos).}

A iniciativa é corajosa e valente, mas quando falha, surge um forte senso de deflação. Ela é animada e entusiástica enquanto dura, mas o instigador da iniciativa muitas vezes é deixado com um senso de inadequação e culpa (p.91).

\section{Diligência vs. Inferioridade (COMPETÊN-} CIA) ( 6-12 anos).

A diligência e competência são capacidades que todos conhecemos bem neste país competitivo (...) Em que você é bom,para que você serve, são as primeiras indagações dos nossos semelhantes. (...) É fundamental ser competente para destacar-se no nosso mundo prático (p.92).

\section{Identidade vs. Confusão de Identidade (FIDELIDADE) (13-20anos).}

Roupas e maquilagem, às vezes, podem ser convincentes, mas no final das contas é somente quando possuímos um senso genuíno de quem somos que mantemos os nossos pés firmes no chão e nossa cabeça erguida, numa elevação da qual podemos ver claramente onde estamos, o que somos e o que representamos (p.92-93)

\section{Intimidade vs. Isolamento (AMOR)(21 anos em diante).}

Os anos de amor e intimidade são brilhantes, ensolarados e cheios de calor. Amar e encontrar-se no outro é algo que traz satisfação e deleite. (...) Nem todos são tão afortunados e abençoados. Um senso de isolamento e privação ataca aqueles para os quais este rico período não é realizado (p.93).
7. Generatividade vs. Estagnação (CUIDADO) (35 anos em diante).

O estágio da generatividade reivindica 0 período de tempo mais longo (...) - trinta anos ou mais, durante os quais a pessoa estabelece um compromisso de trabalho e talvez comece uma nova família, dedicando tempo e energia a incrementar sua vida sadia e produtiva. Durante esse período, o trabalho e os relacionamentos familiares confrontam a pessoa com os deveres de cuidador e uma crescente variedade de obrigações e responsabilidades, interesses e celebrações ( p.94 ).

8. Integridade vs. Desespero,Desgosto (SABEDORIA) (60 anos em diante).

A integridade (...) exige tato, contato e toque.(...) É necessário o tempo de uma vida para se aprender a ter tato e isso exige paciência e habilidade. (...) Conforme Erik nos lembra: "O desespero expressa o sentimento de que otempo agora é curto, curto demais para a tenta-tiva de iniciar uma outra vida e experimentar caminhos alternativos..."(p.94-95).

A partir daí Fowler formula seus estágios da fé (Fowler, 1992/1981).Vamos apresentá-los aqui com frases descritivas retiradas de seu texto. Acrescentaremos para cada estágio um resumo elaborado por nós, na perspectiva desta pesquisa.

\section{Pré-estágio - Lactância (0-1 ,5), Fé Indiferen- ciada}

As sementes da confiança, coragem, esperança e amor fundem-se de uma forma indiferenciada e contendem com ameaças de abandono sentidas pelo bebê, inconsistências e privações no ambiente da criança (p.106).

Os significados da fé estão implícitos na confiança básica e na experiência relacional da mutualidade.

\section{Estágio 1 - Primeira Infância (2-6), Fé Intuiti- vo-Projetiva.}

O que caracteriza a fé neste estágio é a capacidade de unificar e captar o mundo da 
experiência em poderosas imagens e conforme ele é apresentado em estórias que registram as compreensões e sentimentos intuitivos da criança no tocante às condições últimas da existência (p.117).

Os significados referentes às condições últimas da existência começam a ser apropriados através de imagens e símbolos sintéticos.

\section{Estágio 2 -Infância (7-12), Fé Mítico-Literal.}

A pessoa começa a assumir para si as estórias, crenças e observâncias que simbolizam pertença à sua comunidade. As crenças são apropriadas com uma interpretação literal, assim como as regras e atitudes morais. (...) $A$ estória torna-se o principal meio de dar unidade e valor à experiência (p.128-129).

Os significados da fé comum do grupo são apropriados principalmente através de história e narrativas.

\section{Estágio 3 - Adolescência(13-21), Fé Sinté- tico-Convencional.}

No estágio 3, a pessoa tem uma "ideologia": um conjunto mais ou menos consistente de valores e crenças, mas não a objetivou para avaliação e,em certo sentido, não tem consciência de possuí-la (p.146).

Os significados da fé se organizam em conjuntos de crenças e valores profundamente sentidos, mas admitidos em virtude da autoridade de pessoas significativas ou grupos de referência (sem uma reflexão crítica especial).

\section{Estágio 4 - Início da Idade Adulta (21-35). Fé Individuativo-Reflexiva.}

[A pessoa] expressa suas intuições da coerência existente em um ambiente último em termos de um sistema explícito de significados. O estágio 4, tipicamente, traduz símbolos para significados conceptuais. Provavelmente dará pouca atenção aos fatores inconscientes que influenciam seus julgamentos e comportamento. A força ascendente do estágio 4 tem a ver com a sua capacidade de refletir criticamente sobre a identidade (eu) e a perspectiva (ideologia)(154).

Os significados referentes ao ambiente último são organizados conceitualmente em função de uma reflexão racional tanto quanto possível crítica.

\section{Estágio 5-IdadeAdulta (35-60). Fé Conjuntiva.}

Implica a integração, no eu e na própria perspectiva, de muita coisa que foi suprimida ou não-reconhecida no interesse da auto certeza e da consciente adaptação cognitiva e afetiva à realidade. (...) Deve haver [agora] uma abertura às vozes do "eu mais profundo" da pessoa. (...) Este estágio luta para unificar os opostos na mente e na experiência. (...) O comprometimento deste estágio com a justiça é liberado dos limites da tribo, classe, comunidade religiosa ou nação (p.166).

Os significados da fé vão além do que pode ser racionalmente afirmado, e existe uma síntese vivencial dos opostos, num nível mais profundo.

\section{Estágio 6 - Maturidade (60 ...). Fé Universali- zante.}

A pessoa engaja-se em gastar e ser gasta para a transformação da realidade atual na direção de uma realidade transcendente. As pessoas que se encaixam no estágio 6 exibem, tipicamente, qualidades que estremecem nossos critérios usuais de normalidade. A sua indiferença à autopreservação, e a vivacidade de seu gosto e percepção da realidade moral e religiosa transcendente, dão às suas ações e palavras uma qualidade extraordinária e freqüentemente imprevisível (p.168-169).

A pessoa se entrega totalmente, com desapegos surpreendentes, à transformação da realidade atual na direção de uma realidade transcendente.

Fowler afirma que esse estágio 6 é muito raro. Dá como exemplos Gandhi, Luther King, Madre Tereza de Calcutá, Thomas Merton dentre outros poucos. Diz que elevem a ser a descrição 
normativa do possa ser a fé em sua realização mais elevada. Parece dizer que, ao menos aqui, não se pode falar de fé em geral, mas que ela se realiza sempre de forma concreta e particular, a pessoa inserindo-se em uma tradição específica (mesmo quando a transforma radicalmente), pois o absoluto se mostra no particular (p.174). Sugere, portanto, que na sua realização mais desenvolvida, a fé quase supõe ou se identifica com uma conversão ao transcendente, que transforma totalmente a visão que o sujeito possa ter de si. Não é possível falar dessa fé a não ser a partir de dentro de uma determinada tradição, e Fowler o faz a partir da sua, que é a fé monoteísta radical da tradição judaico-cristã (ver p.175, por exemplo).

Como se pode notar, Fowler segue bastante de perto a divisão de Erikson, mas reúne em seu estágio da primeira infância os dois de Erikson para essa idade (autonomia vs. vergonha e dúvida, e iniciativa vs. culpa).

A perspectiva de Fowler ainda é a de uma abordagem formal de estruturas que se constróem sucessivamente, uma dependendo da outra, em estágios bem definidos. O que pretendemos expor aqui, ao contrário, é uma hipótese mais descritiva (do desenvolvimento religioso como ele se apresenta). Por isso não falaremos de estágios formais ou estruturas, mas sim de fases ou etapas que se caracterizam por desafios que estão sendo enfrentados. As etapas que definimos acompanham, no entanto, os estágios de Fowler, com algumas modificações. Falamos da fase do bebê, no primeiro ano de vida, da criança, entre 2 e 6 anos, do menino/a, dos 7 aos 12 aproximadamente, do adolescente, dos 13 aos $18 / 20$, do jovem adulto, dos 21 aos 30 mais ou menos (acolhendo até aqui as divi-sões de Fowler). Colocamos em seguida o adulto propriamente dito, entre os 30 e os 45/50 (mais preocupado com o gerar e cuidar), e o adulto maduro dos $45 / 50$ aos 60 mais ou menos (já numa segunda adolescência, como vimos), separando duas fases no estágio adulto de Fowler. E, por fim, o adulto mais velho, após os 60 mais ou menos, que diferenciamos da etapa de proximidade da morte, que nos pareceu ter características típicas (relaciona-das com um posicionamento especial diante da morte/vida), também separando duas etapas no estágio da maturidade de Fowler. Nossa hipótese descreve 9 etapas.

Estávamos trabalhando nessas etapas quando tivemos contato com o trabalho de Oser e Gmünder (cf. Oser \& Reich, 1996). Eles também estão preocupados com a caracterização de estágios formais (mais ou menos independentes de idade), enfocando, agora, o desenvolvimento do julgamento religioso.

Kohlberg falava de julgamento moral. Mas, segundo Oser e Reich, ele chega a falar de um estágio 7, além dos 6 que descreveu, só que não mais moral, e sim religioso. Este estágio surgiria com a pergunta de transição: "por que ser justo num mundo tão injusto?". Esta passagem começa com o desespero, pois é ele que "nos ajuda a vermo-nos a nós mesmos da distância de um ponto de vista cósmico ou infinito" (p.369). A resposta àquela pergunta, então, se daria a partir de uma "experiência contemplativa de uma multiplicidade não dualística" (id.). Estaria se baseando "num senso de ser parte do todo da vida e na adoção de uma perspectiva cósmica, oposta à perspectiva universal humanística do estágio 6" (id.). Kohlberg cita aqui uma frase espinosiana: "se amamos a Vida ou a Natureza ou Deus, tomamo-nos capazes de superar todos os sofrimentos da vida" (id.). É um estágio "religioso" entre aspas porque, embora freqüentemente seja expresso nos termos de uma união com Deus, não precisa ser necessariamente assim.

Pois bem, se para Kohlberg o desenvolvimento moral é um pré-requisito necessário mas não suficiente para o estágio religioso, para Oser e Gmünder o desenvolvimento religioso tem sua estrutura própria baseada na relação de cada um com a Realidade Última. O desenvolvimento moral refere-se mais às relações eu-tu e é focalizado na superação do sofrimento decorrente da injustiça humana, enquanto o desenvolvi- 
mento religioso refere-se mais às relações com a natureza, estando focalizado na superação do sofrimento resultante de eventos naturais, má sorte e contingências (eventualidades ou acasos). O julgamento religioso é bem diferente do julgamento moral. Trata-se da interpretação da experiência, numa situação concreta de vida, no que diz respeito ao relacionamento com a Realidade Última. Normalmente qualquer acontecimento que faz apelo a um fazer sentido, pode desencadear um julgamento religioso.

Isso estando claro, Oser e Gmünder descrevem 5 estágios do julgamento religioso. Vamos apresentá-los aqui ilustrando com as 5 maneiras estruturalmente sucessivas de se responder à pergunta pelo sentido particular de um acontecimento que nos toca. O que faz que isso aconteça? Que sentido tem isso? Estaremos utilizando frases a partir do artigo citado de Oser e Reich (1996).

Estágio 1: O Ser Último faz isso acontecer. - Há um Ser Último (Deus, para os crentes religiosos) que protege a pessoa ou lhe envia algo maléfico, que lhe dá saúde ou doença, alegria ou desespero. O Ser Último influencia a pessoa (e todos os outros seres vivos) diretamente . A vontade do Ser Último pode sempre serrealizada (p.372) -A pessoa concebe a relação com o Ser Último como um experienciar passivo do que Ihe está sendo enviado. É o estágio do Deus ex machina (p.372).

Os significados religiosos se referem a coisas externas ao sujeito, que podem afetá-lo, mas sobre as quais ele não tem poder algum.

Estágio 2: O Ser Último faz isso acontecer se... - O Ser Último pode ser influenciado por preces, oferendas, obediência a regras religiosas etc. Se alguém é cuidadoso com o Ser Último e passa nos testes, Ele envia, Ele age como um pai confiável e amoroso, e a pessoa será feliz, saudável, cheia de sucesso etc. O indivíduo pode influenciar o Ser Último, ou pode não fazer isso, dependendo de suas necessidades e livre vontade. (p.372) - A pessoa se dá conta de que pode influenciaro Ser Último e sabe como fazer isso. É o estágio do Do ut des (p.372).

Os significados religiosos se referem a coisas externas ao sujeito, que podem afetá-lo, mas ele pode ter alguma influência sobre isso através de atos.

Estágio 3: O Ser Último e os seres humanos fazem isso acontecer. - O indivíduo assume a responsabilidade por sua vida e pelos assuntos do mundo. Liberdade, significado e esperança, estão ligados a decisões da pessoa. O Ser Último está à parte disso. Ele tem seu próprio campo de ação; nós temos o nosso. O Ser Último em sua totalidade inclui uma liberdade, uma esperança e um significado que são diferentes daqueles dos seres humanos. A transcendência está fora do indivíduo, mas representa uma ordem básica do mundo e da vida. (p.372) - O Ser Último e os humanos são vistos como independentes, numa espécie de coexistência pacífica. É o estágio do Deismo (p.372).

A religião, enquanto relação com as coisas a que se referem os significados religiosos, e a vida cotidiana do sujeito, existem, mas são separadas: uma não tem nada a ver com a outra.

Estágio 4: Os seres humanos fazem isso acontecer graças à atuação do Ser Último. Agora uma relação indireta, mediata, com o Ser Último começa a existir. O indivíduo continua a assumir responsabilidade mas ele se questiona sobre as condições de possibilidade de ter responsabilidade. Ele vê seu envolvimento como forma de ultrapassar a falta de significado e esperança, assim como de ultrapassar o absurdo. A transcendência agora está parcialmente dentro (imanência): através do Plano Divino, o Ser Último se torna a condição de possibilidade da liberdade humana, da independência humana, etc. (p.372) - Uma nova relação emerge. Depois de ter visto diversas facetas da vida, o indivíduo integra a Realidade Última em sua vida de um modo novo. Dizer que a natureza da Realidade Última assegura a autonomia pessoal, ajuda a desenvolver a crença de que, de alguma forma, as coisas vão dar certo no futuro 
(Plano Divino). É o estágio da Autonomia mediada (p.372-373).

Religião e vida se diferenciam mas são intimamente relacionadas. O sujeito de alguma forma se vê como instrumento das realidades do mundo religioso. Por exemplo: Deus atua por intermédio dele ou de outras pessoas.

Estágio 5: Os humanos fazem isso, e essa é a verdadeira manifestação do Divino. - O Ser Último (Deus) aparece em todo envolvimento humano embora o transcenda ao mesmo tempo. O Ser Último se torna aparente na história e na revelação. Transcendência e imanência interagem completamente. Esta total integração torna possível a solidariedade universal com todos os seres humanos. O "reino de Deus" se torna o código para um completo e pacífico envolvimento do potencial humano, o qual cria significado não em opções afastadas do mundo, mas, ao contrário, numa perspectiva verdadeiramente social. (p.372) - A complementariedade dos pólos de cada par é plenamente percebida: não há nada profano nem sagrado, não há santidade nem aspectos profanos; não há espe-rança sem absurdo, nem absurdo sem esperan-ça. O Último é experienciado em relacionamen-tos. É o estágio da religiosidade intersubjetiva (p.373).

Religião e vida não se distinguem, são a mesma coisa. A plenitude da vida se dá com a presença das realidades do mundo religioso. Por exemplo: é no mais profundo de mim mesmo que encontro a Deus; ou, tomo consistência verda-deiramente no meio divino; ou, sou uma partici-pação ao Ser.

As descrições feitas por Oser e Gmünder foram também em parte assumidas em nossa hipótese.

\section{HIPÓTESE GERAL DO DESENVOLVIMENTO RELIGIOSO}

Nossa hipótese se apresenta de forma descritiva, situando o desenvolvimento religioso em cada etapa do desenvolvimento pessoal, tomando como foco a formação e evolução de um conceito de eu. Religião é aqui entendida no sentido subjetivo de vivência que o sujeito tem de uma relação com a realidade última, seja em termos estritamente religiosos, quando essa realidade é tematizada como algo além daquilo que se tem acesso pelos caminhos ordinários da ciência ou do conhecimento cotidiano, seja em termos quase religiosos, quando a energia investida é de grande intensidade, globalizante ou totalmente envolvente. A fase de desenvolvimento de certa forma determina as possibilidades dessa vivência. No entanto ainda sobra margem para uma variação grande no tipo de presença psicológica da religião, mesmo supondo-se que sua forma seja a mesma. Como dissemos: o grau de enraizamento da religião pode variar bastante, e, conseqüentemente, sua importância psicológica. A própria descrição deixará isso mais claro.

Depois da descrição de cada etapa do desenvolvimento, apresentaremos um resumo em tópicos para facilitar o trabalho com os depoimentos. As idades assinaladas são evidentemente aproximações por vezes grosseiras.

\section{Etapa do bebê ( 0 a 1,5 anos)}

O desafio central a ser enfrentado no processo de formação de um eu consciente, no primeiro ano de vida, apresenta-se como um passar do sonho à realidade, e descobrir um mundo independente do eu. A experiência bási-ca que está intimamente ligada à superação deste desafio, é a experiência de uma confiança fundamental, tecida noaconchego da relação com os pais, e capaz de tirar a pessoa de dentro de si mesma, e fazê-la viver neste mundo.

Essa confiança básica é o fundamento de todas as formas posteriores de fé ou religião. Falhas aqui (a recusa, a hesitação, ou a negociação da confiança) terão conseqüências na possibilidade de uma autêntica experiência religiosa posterior. Se vier a ocorrer uma tal expe- 
riência, no entanto, ela terá reconstruído em si mesma a própria confiança básica, e além disso, em qualquer caso, a confiança básica será re-significada: aquilo em que a pessoa confia de forma absoluta, será reconhecido experiencialmente (nem sempre com conceitos) como absolutamente transcendente.

No bebê, contudo, não tem muito sentido falar-se de religião do sujeito, a não ser como totalmente implícita na confiança básica, ou

Desafio central: passar do sonho à realidade, descobrir um mundo independente do eu (elaborar a diferenciação eu-mundo).

Necessidades predominantes: fisiológicas e de proteção ou segurança.

Experiência básica: experiência de confiar.

Conseqüência: manipular realisticamente os objetos do mundo.

Religião: é apenas da família; vai passando para o bebê através dos gestos de cuidado, na medida em que é inspiradora deles.

Enraizamento da religião: só existe uma potencialidade religiosa, implícita na confiança básica, e não ainda uma religião do bebê propriamente dita

então como religião da família. Em qualquer outro sentido ela é uma realidade externa.

Etapa da criança (2 a 6 anos)

O desafio central no processo de formação de um eu é, agora, o de superar um relacionamento possessivo, marcado pelo ciúme, e abrir-se a uma relação propriamente dita, onde o outro é aceito em sua separação e autonomia. A experiência que está intimamente ligada com esse tipo de descoberta, é a experiência da linguagem, enquanto reconstrução simbólica interior do mundo. Isso acontecendo, a criança se abrirá para a cooperação e o diálogo, e o eu se aceitará como não único.

A religião estará encontrando suas primeiras expressões simbólicas concretas, a partir do que vai sendo recebido. Mais tarde, se houver uma experiência religiosa especifica, a pessoa virá a reconhecernos "símbolos de sua fé" as formas essenciais de expressão de seu vivido. A não ocorrência da experiência da linguagem, ou uma ocorrência limitada (por exemplo, o predomínio de uma linguagem convencional e não expressiva), impedirá ou dificultará a existência de uma religião refletida, e a pessoa se manterá numa perspectiva imediatista.

Na idade da criança, embora os símbolos sintéticos das realidades do mundo religioso (referente aos significados últimos) já possam ir fazendo algum sentido para ela, as coisas significadas por eles são provavelmente vivenciadas ainda como externas, e carregadas de poder sobre ela.

Desafio central:passar do ciúme à relação, aceitar o outro enquanto separado.

Necessidades predominantes: de proteção ou segurança.

Experiência básica: linguagem, enquanto separação e reconstrução simbólica do ausente.

Conseqüência: inícios de cooperação e diálogo.

Religião:a religião da família começa a ser apropriada através de símbolos (ou ritos, ou imagens sintéticas) que resumem seu significado.

Enraizamento da religião:os objetos significados pelos símbolos religiosos são sentidos como externos e dotados de um poder absoluto sobre a criança.

Etapa do menino/a (dos 7 aos 12 anos)

Etapa do menino/a (dos 7 aos 12 anos) 
O desafio central é passar da inabilidade e passividade para a competência e iniciativa, descobrir-se ativo e capaz, ousarfazer. Se es-se desafio for superado de forma satisfatória, desenvolve-se a segurança interior e a auto-estima.

A religião (ou quase religião) começa a se expressar agora através de histórias que condensam seu sentido. Falhas na experiência da iniciativa e da ousadia, dificultam o acesso ao sentido das histórias e uma posterior identificação do adulto através da inserção em uma tradição (a não ser que uma experiência religiosa forte, posterior,venha suprir essas deficiências).

Nessa idade, embora já possa ir havendo uma apropriação do sentido das narrativas que expressam o sentido último, esse significado se

Desafio central: passar da inabilidade e passividade para a competência e hábilidade, descobrir-se ativo e capaz.

Necessidades predominantes: de proteção ou segurança e participação ou afeto.

Experiência básica: coragem e iniciativa.

Conseqüência: segurança interior e autoestima.

Religião: vai sendo apropriada agora também através do sentido de narrativas, histórias que são contadas.

Enraizamento da religião: embora os objetos significados permaneçam externos e dotados de poder, existe a possibilidade de uma influência sobre eles por parte do sujeito (no caso explicitamente religioso, através de preces, ritos, obediência a preceitos etc.).

refere ainda, provavelmente, a realidades externas. Contudo a relação com essas realidades já não é de mera passividade: existe a possibilidade de uma influência por parte do sujeito (no caso explicitamente religioso, através de preces, ritos, obediência a preceitos, etc.).

Etapa do/a adolescente (dos 13 aos 18/20 anos)
Agora a confiança básica levará o adolescente, ou a adolescente, no processo de formação de um eu, ao desafio de passar de uma vivência de indefinição, para a de uma definição a partir de si, descobrindo uma verdade pessoal mais profunda. A experiência que se relaciona com isso é a da escolha pessoal.

Nesta época a religião (ou qualquer ideologia referente ao sentido último das coisas), como parte da identidade recebida, tende a ser questionada. Deficiências na experiência de escolha bloqueiam esse questionamento e a possível reconstrução posterior de formas mais pessoais dessa atitude básica. Poderá haver um abandono da prática religiosa (ou quase religiosa) dos pais, justamente porque é dos pais, e não ligada a uma escolha (freqüentemente mediada pelo grupo). Esse abandono será provisório ou definitivo,dependendo em parte da autenticidade dos pais, e de seu apoio às experiências dos filhos.

É possível também que a religião (enquanto relação com as coisas às quais se referem os significados religiosos ou últimos) por um lado, e a vida pessoal do sujeito, por outro lado, sejam concebidas ou experienciadas ambas como reais mas separadas e independentes. A pessoa

Desafio: passar de uma indefinição (ou definição a partir de fora), para uma definição a partir de dentro, descobrir uma verdade pessoal mais profunda.

Necessidades predominantes: participação ou afeto, e estima ou valor.

Experiência básica: escolha pessoal.

Conseqüência: ação mais eficaz e realista.

Religião: começa a ser questionada juntamente com toda a identidade recebida; busca de uma religião definida a partir de escolhas pessoais.

Enraizamento da religião: está relacionado com o grau de pessoalidade das escolhas; é uma idade de experiências provisórias. 
vai assumindo mais suas escolhas, e o "mundo religioso" é externo a isso, pertence a outra esfera. Mas também pode acontecer que uma experiência religiosa específica aproxime essas duas esferas.

Etapa do/a jovem adulto/a (dos 18/20 aos 30 aproximadamente)

O desafio central será o de abrir-se para uma relação mais pessoal e profunda, associada à experiência de intimidade. Essa relação não se limita a pessoas; estende-se ao mundo, aos acontecimentos, e descobre algo como uma essência concreta das coisas.

Aqui não é mais possível sustentar uma postura religiosa diante da vida sem que ela seja baseada em uma experiência pessoal, mais crítica e refletida. Práticas religiosas anteriores já não resiste às exigências do jovem adulto, assim como qualquer ideologia superficialmente vivida sem conexão vivencial com a pessoa. Uma carência de intimidade aqui (em toda a amplidão da experiência de intimidade) afetaria todo o resto do desenvolvimento, inclusive o religioso.

Desafio: passar de um relacionamento superficial a uma relação mais profunda, descobrir a essência concreta do outro.

Necessidade predominante: de participação ou afeto e de estima ou valorização.

Experiência básica: intimidade (com péssoas, coisas, acontecimentos, teorias...).

Conseqüência: relações significativas.

Religião: não se sustenta mais uma religião ou sistema de crenças que não seja fundamentada racionalmente e experiencialmente (a não ser que a pessoa simplesmente permaneça com formas anteriores ou convencionais).

Enraizamento da religião: com aquela fundamentação, inicia-se uma aproximação, maior ou menor, entre religião e vida.
Essa é, pois, a idade em que a experiência pessoal do significado torna-se decisiva para o desenvolvimento. Não havendo isso, o sujeito pode ficar apenas com posições religiosas mais ou menos convencionais, ou então será levado a abandonar qualquer posicionamento explícito nesse campo. Por isso mesmo os conceitos religiosos, quando agora mediados por experiência e reflexão, tendem a aproximar religião e vida. Começa a haver uma integração que, se o desenvolvimento estiver sendo satisfatório, estará sendo trabalhada durante toda a vida adulta.

Etapa do adulto (dos 30 aos 35/40 mais ou menos)

Há uma continuação da etapa anterior, consolidando-a na fecundidade: a produção de frutos. O desafio central agora, na formação de um eu, é gerar e cuidar, vivenciando esse novo lado de si próprio que se expande no fruto produzido. O não cumprimento dessa tarefa de desenvolvimento tende a produzir o adulto estéril, sem uma participação criativa no meio. Isso se reflete no âmbito do religioso.

Se houver uma vivência religiosa autêntica ela tende a se expandir no meio, criativamente, num sentimento de integração maior (talvez no

Desafio: passar da esterilidade à fecundidade, descobrir-se gerador ("pai").

Necessidade predominante: de estima, produção ou realização.

Experiência básica: gerar (produzir) e cuidar.

Conseqüência: ampliação e expansão social.

Religião: expandindo-se criativamente em atividades externas ou internas (quando não ficou estacionada em formas anteriores).

Enraizamento: tende a se aprofundar, aproximando o sistema de crenças e orientação com a vida concreta da pessoa. 
sentido de se sentir um instrumento de uma força superior ou um desígnio maior, ou de perceber os outros ou os acontecimentos, como instrumentos desse um desígnio). Mas também pode ocorrer de a pessoa não mais estar integrando a dimensão religiosa explícita em sua vida.

Etapa do adulto maduro (dos $35 / 40$ aos 60 aproximadamente)

Freqüentemente ocorre nessa época um questionamento de tudo e um recomeço em novas bases. O desafio central na transformação do eu é superar as rotinas e os padrões assumidos e encontrar um sentido mais pessoal para a vida, relativizando as normas e os papéis sociais. As reviravoltas na vida da pessoa nessa época, são sentidas como libertação.

Do ponto de vista religioso, esse novo apelo pode levar a uma fé mais pessoal, supe-rando aspectos rígidos e estereotipados, ou então pode levar a um abandono da religião até então professada (caso não haja um apoio conceitual ou experiencial para essas transfor-mações).

Desafio: passar do tédio das rotinas para a alegria da liberdade, descobrir um sentido pessoal para o que se faz.

Necessidade predominante: auto-reali-zação.

Experiência básica: da liberdade e do sentido pessoal.

Conseqüência: alegria, discernimento.

Religião: superação de seus aspectos rígidos e estereotipados (podendo até levar a um abandono se não houver um bom apoio experiencial ou conceitual) e centração numa

Mas pode ocorrer também que a vivência religiosa esteja fixada em formas de etapas anteriores.
Se houver a passagem para uma fé mais pessoal, um passo a mais estará sendo dado na direção da integração entre religião e vida.

Etapa do adulto mais velho (dos 60 aos 80 mais ou menos)

No processo do eu a pessoa é chamada a aprofundar a libertação a partir de todos os apegos. A confiança básica leva a descobrir a vida simplesmente, para além dos apoios externos, e daí a sabedoria, para além da ciência.

O sistema de orientação, religioso ou não, se relativiza enquanto sistema. O conceito é, cada vez mais, vivido apenas como instrumento da experiência. Há uma premência maior na busca de um realmente último, na linha da necessidade de transcendência (talvez provocada pela desproporção entre as aspirações profundas e as perdas). A necessidade de sentido tende a se tornar explicitamente religiosa (embora os conceitos possam variar). Se a vivência religiosa explícita, não recuou para formas rígidas, ela será agora expressão de uma relação experimentada na humildade diante do mistério.

Desafio: passar dos apegos à libertação, descobrir o que é simplesmente viver.

Necessidade predominante: auto-realização e transcendência.

Experiência básica: viver, vitalizar.

Conseqüência: serenidade (além do prazer), sabedoria (além da ciência).

Religião: torna-se agora a expressão de uma relação experimentada na húmildade diante do mistério (caso não tenha recuado para formas anteriores).

Enraizamento: a integração entre religião e vida é tal que esses dois âmbitos tendem a se fundir: viver é estar ligado, ou re-ligado.

Caso isso não ocorra é provável que a pessoa viva em revolta ou amargura. 
Na melhor das hipóteses a integração entre religião e vida tende a ser tal que esses dois âmbitos da experiência caminham para se fundir. Viversimplesmente(semnenhum outro apoio, utilidade ou finalidade) é a forma de estar ligado ou re-ligado (ou a forma de religião).

\section{Etapa da proximidade da morte (...)}

Nesta situação a pessoa vivencia momentos muito especiais em termos de desenvolvimento religioso ou humano pessoal. $\mathrm{O}$ desafio é, na verdade, passar da vida i ndividual para algo radicalmente diferente, e entregar-se empaznessapassagem. Casoocorraissohaverá uma progressiva transcendência do eu empírico com a aceitação da auto-dissolução, e uma abertura para o totalmente outro. A prepa-ração para a entrega absoluta, ou ela própria, se constituem no supremo ato religioso (ou implicitamente religioso quando a referência ao transcendente não é conceituada). A revolta, ou a

Desafio central: passar da vida para a morte, aproximar-se do significado do todo.

Experiência básica: entregar-se (devolver a vida).

Conseqüência: dissolução doeu empírico.

Necessidade predominante: de transcendência.

Religião: fica totalmente relativizada ao seu objeto (agora vivido em sua proximidade imediata); assume plenamente seu caráter de expressão da relação quase direta com o mistério.

Enraizamento: a entrega total e confiante é o supremo ato religioso, capaz de resgatar todas as respostas aos desafios anteriores.

tentativa de segurar-se, podem tornar os últimos tempos de vida ou o ato de morrer, extremamente tormentosos. Mas também é possível que a eminência da passagem reconstrua total- mente, na aceitação, as respostas aos desafios da vida.

Quando os desafios são superados, religião e vida não mais se distinguem experiencialmente (embora possa haver conceitos que não atendam à totalidade desta experiência).

Essa hipótese tem alguns eixos teóricos, dos quais destacamos alguns.

1) O religioso, tal como entendido aqui, não é algo que se acrescente ao humano como um elemento estranho. Pelo contrário, ele aparece na linha do próprio desenvolvimento pessoal, como uma exigência quase natural.

2) Psicologicamente falando, a religião pode ser promotora ou bloqueadora de desenvolvimento. Isso dependerá de sua qualidade humana. Há possibilidade de um trabalho pessoal em direção a uma autenticidade maior da vivência religiosa.

3) Depois da juventude não é mais possível uma religião coerente com os desafios da idade, que não seja fundamentada experiencial e reflexivamente. As formas religiosas que, a partir daí, não forem assim caracterizadas, serão imaturas do ponto de vista psicológico.

4) Nas etapas mais avançadas do desenvolvimento pessoal, o seu lado humano e o seu lado religioso coincidem. Mas há a possibilidade de uma experiência religiosa que não seja elaborada com conceitos propriamente religiosos; ou seja, há a possibilidade de uma religião implícita em uma fé humana aberta a um sentido último.

Este artigo será seguido por outro onde essa hipótese geral do desenvolvimento religioso será tomada como referencial teórico para a leitura de vários depoimentos sobre história religiosa pessoal. Após essa análise de depoimentos, que mostrará a utilidade dessa hipótese, será feita uma discussão final.

\section{REFERÊNCIAS BIBLIOGRÁFICAS}

AMATUZZI, Mauro (1988). Retratos da Vida: caminhos de Crescimento e Ajuda. $2^{a}$ ed.São 


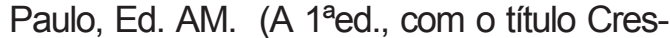
cimento e Ajuda: veredas em Psicologia, da Cortez editora, é de 1980).

AMATUZZI, M; ECHEVERRIA, D; BRISOLA, E; \& GIOVELLI, L. (1996). Psicologia na Comunidade: uma experiência. Campinas, SP, Ed. Alínea.

AMATUZZI, Mauro (1998).A experiência religiosa: busca de uma definição. Estudos de Psicologia, 15 (1), p.49-65.

AMATUZZI, Mauro (1998).A experiência religiosa: estudando depoimentos. Estudos de

CAMINO, Cleonice P. dos S. (1998). Educação Moral: doutrinação ou debate? In: DE MOURA, Maria Lúcia S., CORREA, Jane; \& SPINILLO, Alina (orgs). Pesquisas Brasileiras em Psi-cologia do Desenvolvimento. Rio de Janeiro, Ed. UERJ,p.111-139.
CASSIRER, E. (1972/1944). Antropologia Filosófica - Ensaio sobre o Homem (Introdução a uma Filosofia da Cultura Humana). Trad. de Dr. Vicente Felix de Queiroz. S.Paulo, Ed.Mestre Jou.

ERICKSON, Erik H. (1998). O ciclo de vida completo. Porto Alegre, SR, Artmed. (Original americano).

FOWLER, James (1992). Estágios da Fé: a psicologia do desenvolvimento humano e a busca de sentido. São Leopoldo, RS, Sinodal. (Original americano de 1981)

FROMM, Erich (1974/1944). Análise do Homem. 9a ed. Trad. de Octávio Alves Velho. Rio de Janeiro, Zahar.

JUNG, Gari G. (1979/1934). O Eu e o Inconsciente. Trad. de Dora Ferreira da Silva. Petrópolis, Vozes. (Obras Completas de C.G. Jung, V.7, T.2).

MASLOW, Abraham H. (s/d.) Introdução à Psicologia do Ser. Rio de Janeiro, Eldorado. (O texto mais recente desta coletânea é de 1963).

OSER, Fritz K. \& REICH, Helmud (Instituto Pedagógico da Universidade de Friburgo, Suíça) (1996). Psychological perspectives on religious development. World Psychology 2(3-4): 365-396.

PIAGET, Jean (1967). Seis Estudos de Psico-logia, Trad. Maria Alice Magalhães D'Amorim e Paulo Sérgio lima Silva. Rio de Janeiro, Forense-Universitária. (Original em francês) 